in vivo $34: 3115-3125(2020)$

doi:10.21873/invivo.12145

Review

\title{
Systemic Review and Meta-analysis of Impact of Splenectomy for Advanced Gastric Cancer
}

\author{
CHIKARA KUNISAKI ${ }^{1}$, SHO SATO ${ }^{1}$, NOBUHIRO TSUCHIYA ${ }^{1}$, JUN WATANABE ${ }^{1}$, \\ TSUTOMU SATO $^{1}$, KAZUHISA TAKEDA ${ }^{1}$, KOHEI KASAHARA ${ }^{2}$, TAKASHI KOSAKA ${ }^{2}$, \\ HIROTOSHI AKIYAMA ${ }^{2}$, ITARU ENDO ${ }^{2}$ and TOSHIHIRO MISUMI ${ }^{3}$ \\ ${ }^{1}$ Department of Surgery, Gastroenterological Center, Yokohama City University, Yokohama, Japan; \\ ${ }^{2}$ Department of Gastroenterological Surgery, School of Medicine, Yokohama City University, Yokohama, Japan; \\ ${ }^{3}$ Department of Biostatistics, School of Medicine, Yokohama City University, Yokohama, Japan
}

\begin{abstract}
Background/Aim: Prophylactic splenectomy has shown no inferiority for tumors not invading the greater curvature side. Despite this, the clinical impact of prophylactic splenectomy for proximal advanced gastric cancer is not clear. This review aimed to clarify the impact of splenectomy for advanced gastric cancer in the upper third of the stomach. Materials and Methods: A systematic review and metaanalysis were conducted based on PubMed and EMBASE databases. The following search terms were used: "gastric cancer" OR "splenectomy" OR upper third of the stomach" OR preservation of the spleen. Results: Out of 765 articles, 18 studies (combined $n=6,341$ ) were included in the analysis. Four randomized controlled trials (RCT) and eight retrospective studies suggested the benefits of spleenpreserving gastrectomy. Six retrospective studies showed no significant benefit of spleen-preserving gastrectomy. Prophylactic splenectomy showed a close association with a higher incidence of postoperative morbidity (pancreatic fistula and anastomotic leakage) with no concomitant improvement in overall survival. Prophylactic splenectomy should not be routinely performed and RCTs are necessary to confirm the impact of splenectomy for $\mathrm{cN}(+)$ at the splenic hilum tumors and tumors invading the greater curvature.
\end{abstract}

This article is freely accessible online.

Correspondence to: Chikara Kunisaki, Department of Surgery, Gastroenterological Center, Yokohama City University, 4-57 Urafune-cho, Minami-ku, Yokohama, 232-0024, Japan. Tel: +81 452615656, Fax: +81 452619492, e-mail: s0714@med.yokohamacu.ac.jp

Key Words: Proximal gastric cancer, splenectomy, overall survival, postoperative complication, review.
Despite the recent decrease in the incidence of gastric cancer globally, it is still the third leading cause of cancer-associated mortality $(1,2)$. Recent years have witnessed a gradual increase in the incidence of proximal gastric cancer in Western and Asian countries (3). Total or proximal gastrectomy combined with adequate lymph node dissection is the standard surgical procedure for proximal gastric cancer. The Japanese Gastric Cancer Treatment Guidelines (ver.4) (4) recommend splenectomy to facilitate complete dissection of No.10 lymph node (D2) for patients with advanced gastric cancer in the upper third of the stomach. Therefore, prophylactic splenectomy is routinely performed even for cNO status at No.10 lymph node in these patients, and pancreaticosplenectomy or splenectomy are employed in patients with advanced proximal gastric cancer with direct invasion of the pancreas or spleen for R0 resection in Japan (5). On the other hand, in Western countries, therapeutic splenectomy has been limitedly performed for clinical lymph node $(\mathrm{cN})$-positive at No.10 lymph node and for a tumor invading the spleen or the pancreas in patients with advanced gastric cancer (6). Taken together, it appears that there is a vast difference in the therapeutic strategy between Japan and Western countries.

The clinical significance of prophylactic and therapeutic splenectomy for advanced gastric cancer in the upper third of the stomach remains unclear. Previous studies reported a high incidence of postoperative complications closely related with mortality following gastrectomy combined with splenectomy (7). Some studies have reported a high incidence of lymph node metastasis in the splenic hilum and underlined the need for prophylactic splenectomy in patients with tumors involving the upper third of the stomach and the gastroesophageal junction (8). On the contrary, some other studies have reported poor long-term survival of patients with lymph node metastasis in the splenic hilum (9). 
Therefore, the relative merits of spleen preservation vis-avis those of splenectomy need to be carefully evaluated in this population.

A previous study reported the survival benefits of prophylactic splenectomy in a subset of patients with advanced gastric cancer in the upper third of the stomach (10). However, another study yielded contradicting results (11). Both of these studies as well as others are retrospective ones with a small sample size and had several limitations, including poor reliability and statistical bias.

In a recent randomized controlled trial, prophylactic splenectomy showed no clinical impact in patients with tumors not invading the greater curvature in the upper third of the stomach (12). However, no randomized controlled trial has focused on the surgical benefits of prophylactic splenectomy on tumors invading the greater curvature in the upper third of the stomach, although some retrospective studies were reported (13).

We conducted this systemic review to clarify the surgical impact of prophylactic splenectomy for a tumor cN0 at No.10 lymph node. Of note, we paid particular attention to the surgical results of splenectomy based on the primary tumor location (the lesser curvature and the greater curvature)

\section{Materials and Methods}

Literature search. A systematic literature search was performed using the PubMed and EMBASE databases (reference period: January 1997 to March 2019). The language of publication was restricted to English, irrespective of the country of research. The following search terms were used: "gastric cancer" OR "splenectomy" OR upper third of the stomach" OR preservation of the spleen. Moreover, the reference lists of retrieved articles were manually screened to identify additional relevant studies.

The reference lists of relevant meta-analyses and primary studies were also searched to identify any studies that were potentially missed. The literature search was independently performed by multiple authors to improve the reliability of the literature search. We only selected comparative studies that focused on the significance of splenectomy for advanced gastric cancer in the upper third of the stomach. Studies that evaluated the general surgical outcomes of overall gastric cancer were excluded. A total of 816 articles were retrieved from the database search and screening of reference lists. After screening of titles/abstracts, 767 articles were excluded while 49 articles were selected for full-text review. Finally, 18 studies with a combined study population of 6,341 patients were selected for the current review (studies with poor quality and those with inadequate number of patients were excluded) (Figure 1). Out of the 18 studies, 4 studies were prospective randomized controlled trials (pRCT) and 14 were retrospective studies. Eight retrospective studies showed a positive effect of spleen-preserving gastrectomy, while 6 retrospective studies showed no benefit of spleen-preserving gastrectomy.

This work has been reported in line with preferred reporting items for systematic reviews and meta-analyses (PRISMA) (14) and assessing the methodological quality of systematic reviews (AMSTAR) (15) guidelines.
Study-selection criteria. The inclusion and exclusion criteria were defined $a$ priori by applying the problem/population, intervention, comparison and outcome (PICO) framework. We selected randomized controlled trials and non-randomized retrospective trials that compared the outcomes between the splenectomy group and the non-splenectomy group for adenocarcinoma mainly in the upper third of the stomach. Patient characteristics, intraoperative findings, short-term outcomes (postoperative morbidity, such as pneumonia, anastomotic leakage, pancreatic fistula, intra-abdominal abscess, and wound infection), and long-term outcomes [overall survival (OS)] were compared between the two groups. Exclusion criteria were as follows: review articles, comments, letters, case reports, cohort studies with fewer than 100 cases, and studies that included patients with other concomitant cancers.

Data were extracted by two authors and confirmed by a $3^{\text {rd }}$ author. In this review, OS was defined as the primary outcome. Postoperative morbidity and mortality were secondary outcomes.

Statistical analysis. Data were analyzed using the SPSS statistical software program (SPSS Inc., Chicago, IL). Patient characteristics were compared using the two-tailed Fisher exact test or the Chisquared test with Yates correction. Quantitative variables are expressed as mean \pm standard deviation and between-group differences were assessed using the Student's $t$-test. The KaplanMeier method was used for survival analysis and between-group differences were assessed using the log-rank test. A random effects model was used for the pooled estimates to account for potential heterogeneity between studies and to adopt a more moderate approach. The pooled effect was considered significant if $p<0.05$. Heterogeneity was assessed using $\mathrm{I}^{2}$ statistic and results were displayed graphically using forest plots. Odds ratios (OR) and $95 \%$ confidence intervals $(\mathrm{CI})$ were calculated using the random-effects Mantel-Haenzel method.

Publication bias of the meta-analysis was assessed by the funnel plot of standard error by log odds ratio. Probability $(p)$-Values $<0.05$ were considered indicative of statistical significance.

\section{Results}

Prospective randomized controlled trials. We found four pRCTs that compared the surgical outcomes between gastrectomy with and without splenectomy (Table I). Of these, two studies were conducted in Japan $(12,16)$, one in Korea (17) and one in Chile (18). These studies had a combined study population of 1,009 patients. OS was not significantly different between the two groups in any of these studies. Sano et al. have conducted a noninferiority trial to identify the impact of spleen preservation (12). They have successfully shown the noninferiority of spleen preservation with respect to OS in a cohort of 505 patients with gastric cancer not invading the greater curvature in the upper third of the stomach. Among these four trials, there was considerable variability with respect to patient characteristics, therapeutic strategies, and postoperative treatments; therefore, surgical outcomes, such as operation time, postoperative morbidity, hospital stay, mortality, and OS, differed between the trials. In each of these trials, there 

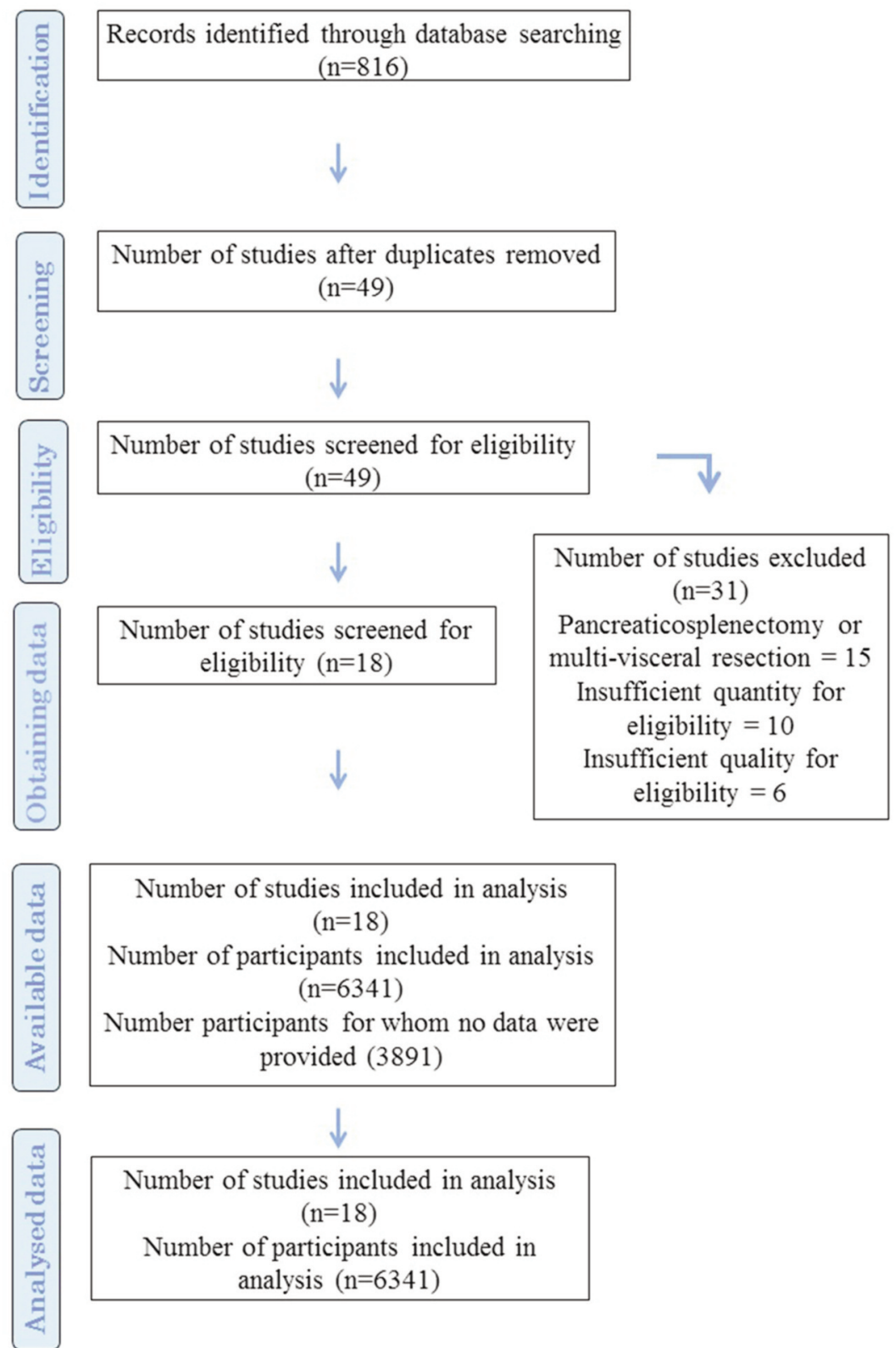

Figure 1. Preferred reporting items for systematic reviews and meta-analysis (PRISMA), 2015 diagram of study selection.

was no significant difference between the splenectomy and the non-splenectomy groups with respect to intraoperative factors or mortality. However, the postoperative morbidity was discernibly higher in the splenectomy compared to the non-splenectomy group. Moreover, the incidence of pancreatic fistula and intra-abdominal abscess were significantly higher in the splenectomy compared to the nonsplenectomy group in two studies. In these four pRCTs, OS was not improved by splenectomy in spite of the high incidence of postoperative morbidity; therefore, they suggest that prophylactic splenectomy should be avoided.

Retrospective studies that showed the benefits of spleen preservation. A total of eight retrospective studies (combined $\mathrm{n}=3,676$ ) showed the beneficial effect of spleen-preserving gastrectomy. Of these, four articles were published from Korea (19-22), three were from China (23-25) and one was from Germany (26). In four studies, the incidence of 
Table I. Outcomes of prospective randomized trials.

\begin{tabular}{|c|c|c|c|c|c|c|c|c|}
\hline \multirow{2}{*}{$\begin{array}{l}\text { Variable } \\
\text { Splenectomy }\end{array}$} & \multicolumn{2}{|c|}{ Furukawa et al. (16), 2000} & \multicolumn{2}{|c|}{ Csendes et al. (18), 2002} & \multicolumn{2}{|c|}{ Yu et al. (17), 2006} & \multicolumn{2}{|c|}{ Sano et al. (12), 2017} \\
\hline & $(+)$ & $(-)$ & $(+)$ & $(-)$ & $(+)$ & $(-)$ & $(+)$ & $(-)$ \\
\hline Patients (n) & 55 & 55 & 90 & 97 & 104 & 103 & 254 & 251 \\
\hline $\operatorname{Sex}(n)$ & $39 / 16$ & $37 / 18$ & $60 / 30$ & $65 / 32$ & & & & \\
\hline male/female & $72 / 32$ & $72 / 31$ & $196 / 58$ & $204 / 47$ & & & & \\
\hline Age (years) (mean) & 57.1 & 57.5 & 62.7 & 62.7 & 57 & 57 & 65 & 65 \\
\hline \multicolumn{9}{|l|}{ Stage (n) } \\
\hline I/II/III/IV & NR & NR & NR & NR & $35 / 21 / 27 / 21$ & $28 / 24 / 27 / 24$ & $94 / 74 / 70 / 16$ & $108 / 70 / 53 / 20$ \\
\hline \multicolumn{9}{|l|}{ Histological type } \\
\hline Diff./Undiff. & $33 / 22$ & $23 / 32$ & NR & NR & $33 / 71$ & $33 / 70$ & $118 / 136$ & $136 / 115$ \\
\hline $\begin{array}{l}\text { Lymph node } \\
\text { metastasis } \\
\quad \text { Positive/negative }\end{array}$ & $31 / 24$ & $31 / 24$ & NR & NR & $63 / 41$ & $66 / 37$ & $148 / 106$ & $144 / 107$ \\
\hline $\begin{array}{l}\text { Operation time } \\
\text { (min.) (mean) }\end{array}$ & 287 & 268 & 218 & 208 & NR & NR & 231 & 224 \\
\hline $\begin{array}{l}\text { Postoperative } \\
\text { morbidity, overall (n) }\end{array}$ & NR & NR & NR & NR & 16 & 9 & 77 & 42 \\
\hline Pancreatic fistula & 8 & 5 & NR & NR & NR & NR & 32 & 6 \\
\hline Anastomotic failure & 2 & 2 & NR & NR & NR & NR & 11 & 8 \\
\hline Intraabdominal abscess & NR & NR & 10 & 4 & 4 & 3 & 20 & 10 \\
\hline $\begin{array}{l}\text { Hospital stay } \\
\text { (days) (mean) }\end{array}$ & 46.1 & 41.0 & 21.6 & 18.4 & 11 & 11 & NR & NR \\
\hline Mortality (n) & 4 & 3 & 4 & 3 & 2 & 1 & 1 & 2 \\
\hline $\begin{array}{l}\text { 5-year overall } \\
\text { survival (\%) }\end{array}$ & 80 & 76.7 & 41.9 & 36.2 & 54.8 & 48.5 & 75.1 & 76.4 \\
\hline Significance & NS & & NS & & $p=0.503$ & & $\begin{array}{c}\mathrm{HR}=0.88, \\
\text { Non-inferiority } \\
p=0.025\end{array}$ & \\
\hline
\end{tabular}

NR: Not reported; NS: not significant; Diff: differentiated; Undiff: undifferentitated.

postoperative morbidity was significantly higher in the splenectomy compared to the non-splenectomy groups (19, $21,22,25)$. Two studies showed no significant betweengroup difference in the incidence of postoperative morbidity $(23,26)$, while two studies did not report on this topic $(20$, 24). A total of five studies reported the comparative outcomes of mortality. There was no significant difference in mortality in four studies $(20,22,23,26)$; however, one study showed barely significant difference in mortality between gastrectomy with and without splenectomy $(2.7 \%$ vs. $0.4 \%$, respectively, $p=0.048$ ) (19). The remaining three studies did not report the outcomes of mortality $(22,24,25)$. All studies showed the superiority of spleen preservation for OS by univariate analysis; however, three studies showed no significant between-group difference in OS on sub-group analysis disaggregated by disease stage (19-21). Moreover, spleen preservation was not identified as an independent favorable prognostic factor for OS. Apparently, these retrospective studies had some limitations. Particularly, patient characteristics were significantly different between the splenectomy and the non-splenectomy groups. The splenectomy group comprised of patients with more advanced stage tumors and postoperative complications were more frequently observed. All studies concluded that splenectomy should be avoided unless a tumor has directly invaded the spleen and stressed the need for a well-designed pRCT (Table II).

Retrospective studies that showed no effect of spleen preservation. A total of six studies (combined $n=1,656$ ) were included in this category. Of these, two articles were published from Japan $(27,28)$, two were from Taiwan (29, 30 ), one was from China (31), and one was from Korea (32). All these comparative studies found no significant difference in OS or mortality between the splenectomy and nonsplenectomy groups. Of these six studies, two studies showed a significantly higher incidence of overall postoperative complications $(28,31)$. These studies concluded that spleen-preserving gastrectomy is feasible for gastric cancer in the upper third of the stomach (Table III).

Meta-analysis. Postoperative complications were obtained from 14 studies. We could extract the data from 2 studies in pRCTs, 6 studies in positively supporting the effect of spleen-preserving gastrectomy, and 6 studies without difference in the effect of the preservation of the spleen. The 
Kunisaki et al: Splenectomy for Advanced Gastric Cancer (Review)

Table II. Retrospective studies positively supporting the effect of spleen-preserving gastrectomy.

\begin{tabular}{|c|c|c|c|c|c|c|c|c|}
\hline Study & Splenectomy & $\begin{array}{l}\text { No. of } \\
\text { patients }\end{array}$ & $\begin{array}{c}\text { Overall } \\
\text { postoperative } \\
\text { complication }(\%)\end{array}$ & $\begin{array}{l}\text { Significance } \\
(p \text {-Value })\end{array}$ & $\begin{array}{c}\text { Mortality } \\
(\%)\end{array}$ & $\begin{array}{c}\text { Significance } \\
(p \text {-Value })\end{array}$ & $\begin{array}{c}\text { 5-year } \\
\text { overall } \\
\text { survival (\%) }\end{array}$ & $\begin{array}{c}\text { Significance } \\
\text { ( } p \text {-Value) }\end{array}$ \\
\hline \multirow[t]{2}{*}{ Kwon et al. (19) } & $(+)$ & 260 & 21.5 & \multirow[t]{2}{*}{0.013} & 2.7 & \multirow[t]{2}{*}{0.048} & NR & \multirow[t]{2}{*}{0.0265} \\
\hline & $(-)$ & 232 & 12.9 & & 0.4 & & NR & \\
\hline \multirow{2}{*}{ Lee et al. (20) } & $(+)$ & 492 & NR & \multirow[t]{2}{*}{ NR } & 0.6 & \multirow[t]{2}{*}{ NS } & 52.9 & \multirow[t]{2}{*}{$<0.001$} \\
\hline & $(-)$ & 173 & NR & & 0 & & 64.8 & \\
\hline \multirow[t]{2}{*}{ Fatouros et al. (26) } & $(+)$ & 67 & 19.4 & \multirow[t]{2}{*}{ NS } & 3.4 & \multirow[t]{2}{*}{ NS } & 40 & \multirow[t]{2}{*}{0.0039} \\
\hline & $(-)$ & 59 & 18.6 & & 0 & & 63 & \\
\hline \multirow[t]{2}{*}{ Zhang et al. (23) } & $(+)$ & 38 & 18.4 & \multirow[t]{2}{*}{0.573} & 0 & \multirow[t]{2}{*}{ NS } & 16.9 & \multirow[t]{2}{*}{0.0079} \\
\hline & $(-)$ & 70 & 14.0 & & 1.4 & & 38.7 & \\
\hline \multirow[t]{2}{*}{ Oh et al. (21) } & $(+)$ & 99 & 29.3 & \multirow[t]{2}{*}{$<0.001$} & 1.0 & NS & MST:56.7 months & \multirow[t]{2}{*}{$<0.001$} \\
\hline & $(-)$ & 267 & 11.6 & & 0.7 & & MST:72 months & \\
\hline \multirow[t]{2}{*}{ Wang et al. (24) } & $(+)$ & 105 & NR & \multirow[t]{2}{*}{ NR } & NR & NR & 21.3 & \multirow[t]{2}{*}{$<0.001$} \\
\hline & $(-)$ & 526 & NR & & NR & & 38.6 & \\
\hline \multirow[t]{2}{*}{ Zhang et al. (25) } & $(+)$ & 100 & 24 & \multirow[t]{2}{*}{0.005} & NR & NR & 28.8 & \multirow[t]{2}{*}{0.013} \\
\hline & $(-)$ & 114 & 10 & & NR & & 33.8 & \\
\hline \multirow[t]{2}{*}{ Jeong et al. (22) } & $(+)$ & 229 & 29.3 & \multirow[t]{2}{*}{$<0.001$} & NR & NR & 55 & \multirow[t]{2}{*}{$<0.001$} \\
\hline & $(-)$ & 845 & 19.8 & & NR & & 81 & \\
\hline
\end{tabular}

NR: Not reported; NS: not significant.

Table III. Retrospective studies without difference in the effect of the preservation of the spleen.

\begin{tabular}{|c|c|c|c|c|c|c|c|c|}
\hline Study & Splenectomy & $\begin{array}{l}\text { No. of } \\
\text { patients }\end{array}$ & $\begin{array}{c}\text { Overall } \\
\text { postoperative } \\
\text { complication }(\%)\end{array}$ & $\begin{array}{l}\text { Significance } \\
(p \text {-Value })\end{array}$ & $\begin{array}{l}\text { Mortality } \\
(\%)\end{array}$ & $\begin{array}{l}\text { Significance } \\
(p \text {-Value })\end{array}$ & $\begin{array}{c}\text { 5-year } \\
\text { overall } \\
\text { survival (\%) }\end{array}$ & $\begin{array}{c}\text { Significance } \\
(p \text {-Value })\end{array}$ \\
\hline \multirow[t]{2}{*}{ Sasada et al. (27) } & $(+)$ & 201 & 27.4 & 0.260 & 0.5 & 1.00 & $\begin{array}{l}\text { Stage I/II/III/IV } \\
=84 / 57 / 28 / 18\end{array}$ & NS \\
\hline & $(-)$ & 148 & 21.6 & & 0 & & $\begin{array}{l}\text { Stage I/II/III/IV } \\
=84 / 60 / 52 / 7\end{array}$ & \\
\hline \multirow[t]{2}{*}{ Yao et al. (31) } & $(+)$ & 51 & 27.5 & 0.05 & 0 & 1.00 & 39.2 & NS \\
\hline & $(-)$ & 61 & 11.5 & & 0 & & 41.0 & \\
\hline \multirow[t]{2}{*}{ Fang et al. (29) } & $(+)$ & 47 & 31.9 & 0.194 & 0 & 1.00 & 57.1 & 0.681 \\
\hline & $(-)$ & 68 & 20.6 & & 1 & & 60.2 & \\
\hline \multirow[t]{2}{*}{ Nashimoto et al. (28) } & $(+)$ & 240 & 34.2 & $<0.05$ & NR & NR & $\begin{array}{c}\text { Stage II/IIIA/IIIB= } \\
62.6 / 53.1 / 41.2\end{array}$ & $\mathrm{NS} / \mathrm{NS} / 0.073$ \\
\hline & $(-)$ & 265 & 21.5 & & NR & & $\begin{array}{c}\text { Stage II/IIIA/IIIB= } \\
73.3 / 69.7 / 72.7\end{array}$ & \\
\hline \multirow[t]{2}{*}{ Wang et al. (30) } & $(+)$ & 172 & 21.5 & 0.889 & 4.1 & 0.711 & 47 & 0.181 \\
\hline & $(-)$ & 291 & 20.9 & & 4.8 & & 51 & \\
\hline \multirow{2}{*}{ Son et al. (32) } & $(+)$ & 68 & 17.6 & 0.572 & 0 & 1.00 & 77.3 & 0.240 \\
\hline & $(-)$ & 44 & 13.6 & & 0 & & 65.9 & \\
\hline
\end{tabular}

NR: Not reported; NS: not significant.

analysis showed that the preservation of the spleen had a lower postoperative complication rate compared to splenectomy $(\mathrm{OR}=0.567,95 \% \mathrm{CI}=0.489-0.658, p<0.000)$ (Figure 2a), with low heterogeneity between studies $\left(p=0.281, I^{2}=15.8 \%\right)$.

Mortality was obtained from 12 studies involving 3,693 patients reported data of mortality. The data from 4 studies in pRCTs, 5 studies in positively supporting the effect of spleen-preserving gastrectomy, and 3 studies without a difference in the effect of the preservation of the spleen were extracted. We could not find significant difference in mortality between the two groups (OR=0.776, 95\% CI $=0.445-1.351, p=0.370$ ) (Figure 2b), with a low heterogeneity between studies $\left(p=0.914, I^{2}=0.0 \%\right)$.

Hazard ratio (HR) for OS was acquired from 8 studies. We could extract the data of HR from one study in pRCTs, 5 


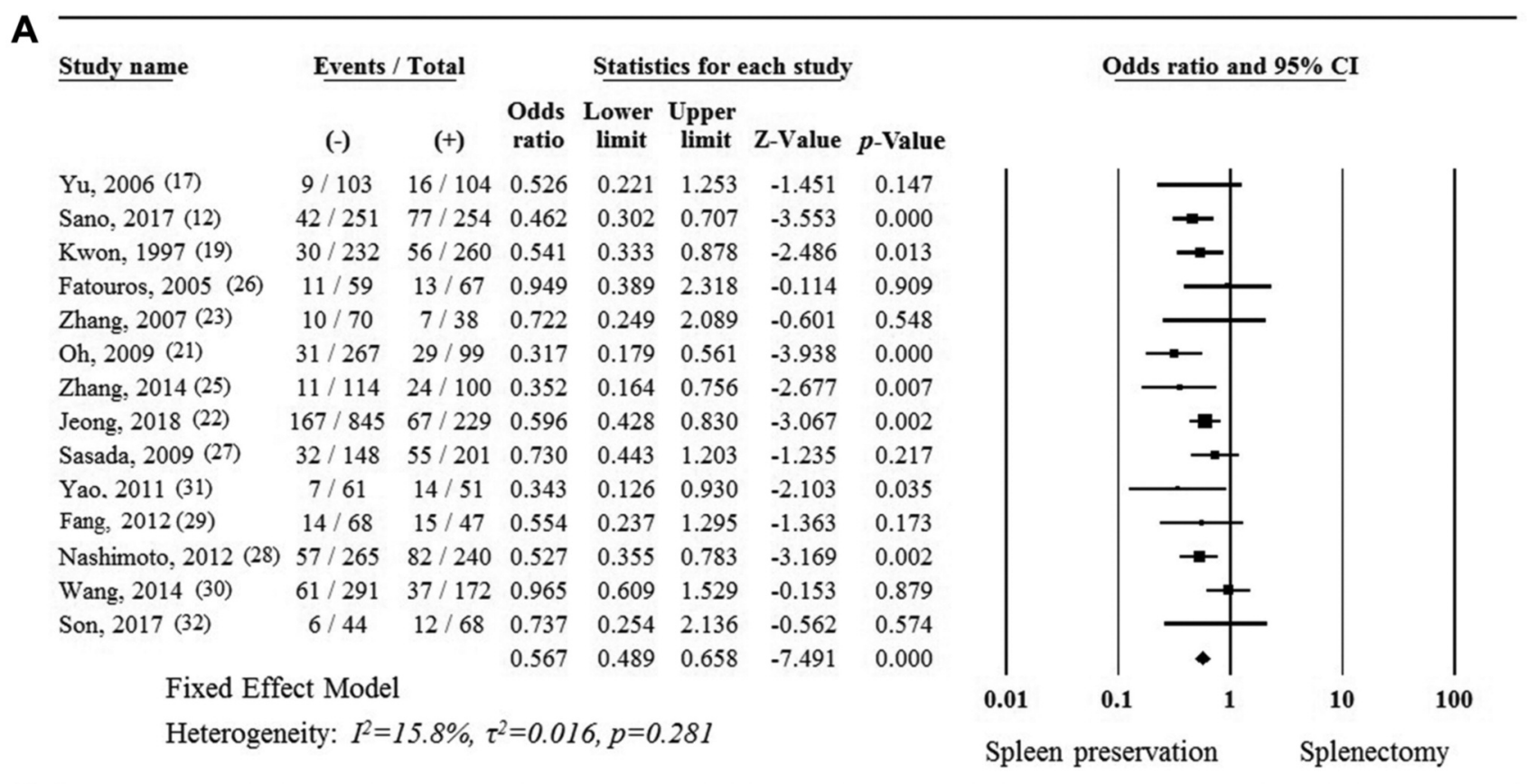

B

\begin{tabular}{|c|c|c|c|c|c|c|c|}
\hline \multirow[t]{2}{*}{ Study name } & \multicolumn{2}{|c|}{ Events / Total } & \multicolumn{5}{|c|}{ Statistics for each study } \\
\hline & $(-)$ & $(+)$ & $\begin{array}{l}\text { Odds } \\
\text { ratio }\end{array}$ & $\begin{array}{c}\text { Lower } \\
\text { limit }\end{array}$ & $\begin{array}{c}\text { Upper } \\
\text { limit }\end{array}$ & alue & 1 \\
\hline Furukawa, 2000 (16) & $3 / 55$ & $4 / 55$ & 0.742 & 0.159 & 3.472 & -0.379 & \\
\hline Csendes, 2002 (18) & $3 / 97$ & $4 / 90$ & 0.686 & 0.149 & 3.156 & -0.484 & 0.629 \\
\hline Yu, 2006 (17) & $1 / 103$ & $2 / 104$ & 0.500 & 0.045 & 5.613 & -0.561 & 0.575 \\
\hline Sano, 2017 (12) & $2 / 251$ & $1 / 254$ & 2.034 & 0.181 & 22.822 & 75 & 0.565 \\
\hline Kwon, 1997 (19) & $1 / 232$ & $7 / 260$ & 0.145 & 0.016 & 1.270 & -1.744 & 0.081 \\
\hline Lee, $2001(20)$ & $0 / 173$ & $3 / 492$ & 0.409 & 0.021 & 7.973 & -0.590 & 0.555 \\
\hline Fatouros, 2005 (26) & $0 / 59$ & $2 / 67$ & 0.197 & 0.010 & 4.089 & -1.049 & 0.294 \\
\hline Zhang, 2007 (23) & $1 / 70$ & $0 / 38$ & 1.639 & 0.065 & 41.443 & 0.300 & 0.764 \\
\hline Oh, 2009 (21) & $2 / 267$ & $1 / 99$ & 0.698 & 0.060 & 8.066 & -0.288 & 0.773 \\
\hline Sasada, 2009 (27) & $0 / 148$ & $1 / 201$ & 0.449 & 0.018 & 11.074 & -0.490 & 0.624 \\
\hline ang, 2012 (29) & $1 / 68$ & $0 / 47$ & 1.653 & 0.059 & 46.089 & 0.296 & 0.767 \\
\hline Wang, 2014 (30) & $14 / 291$ & $7 / 172$ & 1.179 & 0.467 & 2.976 & 0.349 & 0.727 \\
\hline & & & 0.776 & 0.445 & 1.351 & -0.897 & 0.370 \\
\hline
\end{tabular}

Fixed Effect Model

Heterogeneity: $I^{2}=0.0 \%, \tau^{2}=0.000, p=0.914$

Spleen preservation Splenectomy 


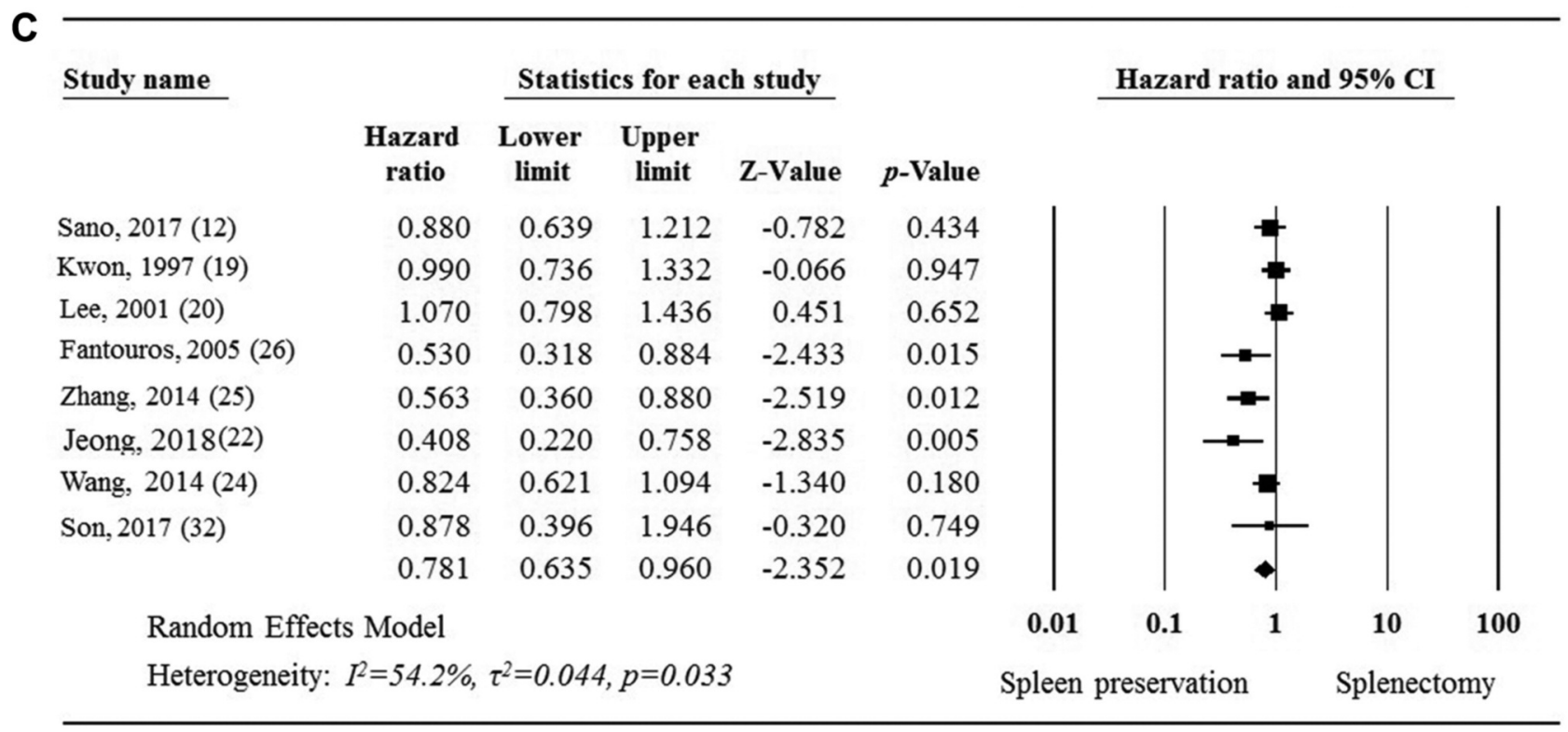

Figure 2. Forest plot of pooled odds ratio. a) Postoperative complications, b) mortality, c) hazard ratio for overall survival.

\section{Discussion}

The present systemic review showed that prophylactic splenectomy does not confer a survival benefit but is associated with a high incidence of postoperative morbidity. Therefore, a well-designed, prospective randomized controlled trial is required to identify cases for which prophylactic splenic hilar lymph node dissection with or without splenectomy can be justified.

The main goal of prophylactic splenectomy is oncological sufficiency. In Japan, prophylactic splenectomy is widely performed to facilitate complete dissection of lymph node at the splenic hilum for gastric cancer clinically without metastasis at No. 10 lymph node in the upper third of the stomach to complete D2 lymph node dissection according to the guidelines (4). As shown in this review, most studies focusing on the significance of prophylactic splenectomy have shown no favorable long-term survival outcomes in the splenectomy group. On survival analysis disaggregated by disease stage, several retrospective studies suggested no significant between-group difference in the 5-year OS according to stage; however, the 5-year OS in the nonsplenectomy group was longer compared to the splenectomy group (17-21). Only a few studies have shown the feasibility of prophylactic splenectomy for advanced proximal gastric cancer irrespective of tumor stage.

In Western countries, therapeutic splenectomy has been employed for tumors invading the spleen and in cases with clinical suspicion of lymph node metastasis at the splenic hilum. One study has demonstrated the prognostic impact of splenectomy in patients with advanced proximal gastric cancer with lymph node metastasis at the splenic hilum (10). Splenectomy showed a benefit in patients with T3 tumors and was found to be an independent prognostic factor for OS; however, this was a retrospective study with some limitations. Moreover, other studies have reported no survival benefit of splenectomy for patients with metastasis at the splenic hilum (9).

No pRCTs have identified the impact of therapeutic splenectomy in patients with advanced proximal gastric cancer who have lymph node metastasis at the splenic hilum; therefore, a randomized study is required to validate the need for therapeutic splenectomy in patients with advanced gastric cancer in the upper third of the stomach.

Many RCTs and retrospective studies have shown significantly high incidence of postoperative complications following splenectomy $(12,16-19,21,22,25)$. Pancreatic fistula, intra-abdominal abscess, and anastomotic leakage are typical complications of splenectomy. The incidence of postoperative complications differed between the studies owing to variable definitions of postoperative complications. Moreover, the sample size, surgeons' skill set, and the quality of treatment influence the outcome. These complications may sometimes lead to mortality and result in poor prognosis. Therefore, there is a need to accurately determine the indications for splenectomy. Other studies have evaluated the predictive factors for lymph node metastasis at the splenic hilum (33). No.4sa lymph node metastasis, cross-sectional location (multi-wall involvement), 

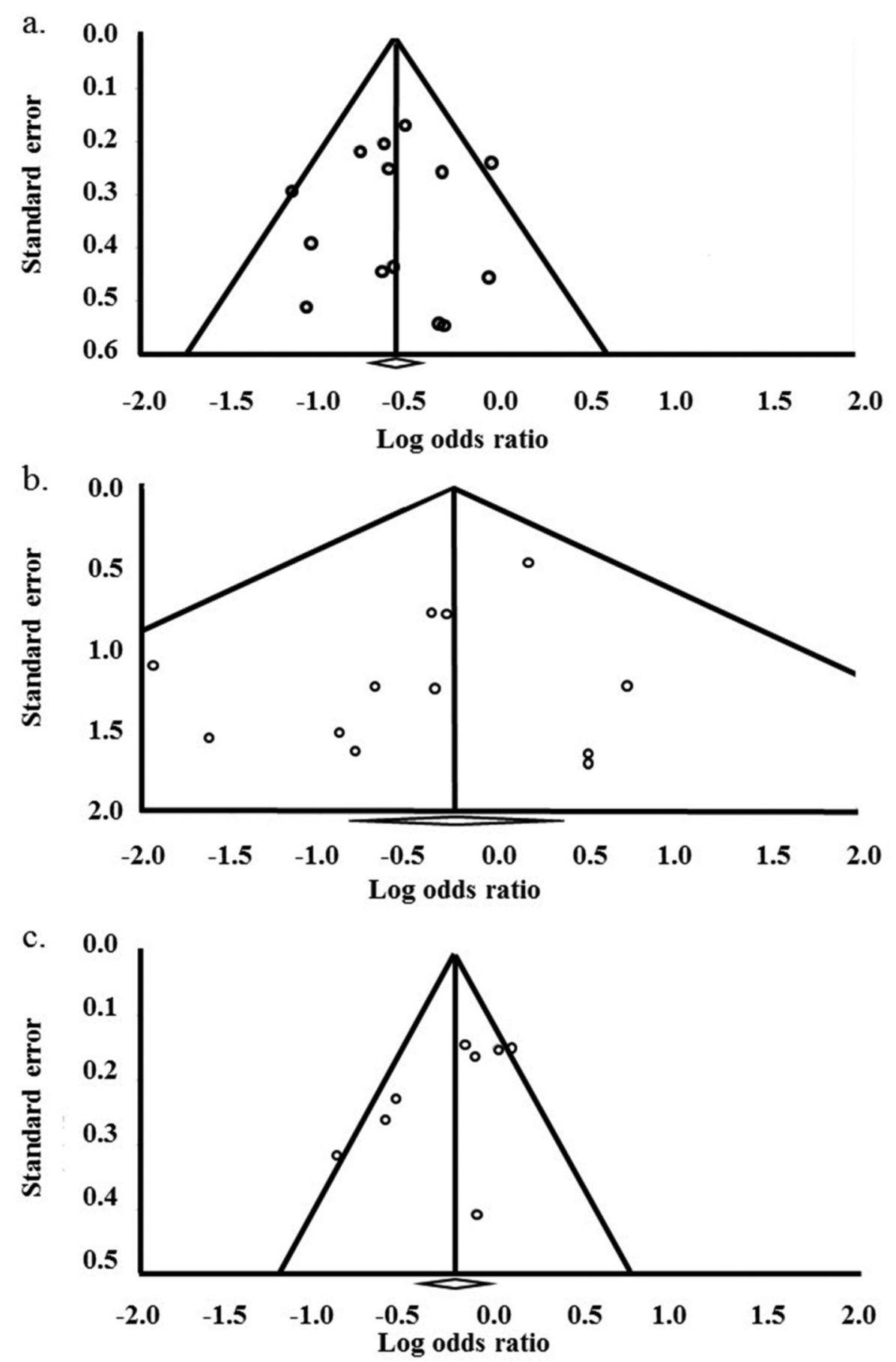

Figure 3. Funnel plot. Publication bias of the meta-analysis was assessed using the funnel plot of standard error by log odds ratio. a) Postoperative complications, b) mortality, c) hazard ratio for overall survival.

tumor diameter, pNstage, and pTNMstage have shown a significant correlation with lymph node metastasis at the splenic hilum. At least, it may be better to perform splenectomy for patients with suspected lymph node metastasis.
A recent RCT suggested the need to avoid splenectomy in patients with proximal gastric cancer and no invasion of the greater curvature; this was because splenectomy increased operative morbidity with no concomitant survival benefit 
(12). This study is the first study that focused on the therapeutic effect of splenectomy based on the location of the gastric tumor. No RCT has evaluated the survival benefit of splenectomy for tumors involving the greater curvature. However, a retrospective study has shown no prognostic impact of prophylactic splenectomy in spite of the higher incidence of morbidity in patients with gastric cancer invading the greater curvature (34). Conversely, two other studies have shown the necessity of lymph node dissection at the splenic hilum by evaluating the favorable therapeutic value index, as defined by the metastatic rate multiplied by the 5-year survival rate (13). The authors argued that complete splenic hilar lymph node dissection with and without splenectomy is recommended because the therapeutic value index of No. 10 lymph node was favorable. A most recent study reported the therapeutic value index in each lymph node station by the macroscopic type (type $4 v s$. non-type 4) in tumors involving the greater curvature (35). The indexes in No.10 lymph node ranked seventh in type 4 and second in non-type 4 tumor. Therefore, they concluded that No.10 lymph node may be the target for dissection in tumors invading the greater curvature. However, these were retrospective studies that are liable to be affected by selection bias. Therefore, a well-designed RCT is required to confirm the validity of hilar lymph node dissection based on the ubiquity of the tumor.

Owing to recent technological advances, laparoscopic and robotic surgery has been widely employed in the field of gastroenterological surgery. One study has reported low rates of postoperative morbidity and favorable long-term survival after laparoscopic total gastrectomy with splenectomy (36). Another study has compared the short-term outcomes of spleen preservation $v s$. splenectomy in a small sample of patients undergoing laparoscopic total gastrectomy (37). This revealed acceptable short-term outcomes in the spleen preservation group. The debate on the subject of splenectomy has gradually moved to the next stage. Recent studies dealt with the operative approach (laparoscopic and robotic) for splenic hilar lymph node dissection but did not discuss the pros and cons of splenectomy itself. Several studies report acceptable morbidity and mortality rates after laparoscopic or robotic hilar lymph node dissection for proximal gastric cancer (38). Clear delineation of the indications for splenic hilar lymph node dissection for tumors invading the greater curvature would facilitate application of these advanced techniques in this population.

In this study there are some limitations. First, retrospective studies comparing short and long-term outcomes between the spleen preservation and the splenectomy groups with many patients are limited. Moreover, some important data were lacking in some studies. Therefore, publication bias was found in this study. Second, the number of patients was relatively small and so the reliability of obtained outcomes might be low in the prospective comparing studies used in this study. It is necessary to conduct a pRCT to clarify whether splenectomy or splenic hilar lymph node dissection would be effective and for what kind of advanced gastric cancer in the upper third of the stomach.

In conclusion, available evidence suggests that prophylactic splenectomy should not be routinely performed in patients with advanced proximal gastric cancer. pRCTs are required to determine the appropriate indications for therapeutic splenectomy or spleen-preserving hilar lymph node dissection in patients with advanced proximal gastric cancer and with $\mathrm{cN}(+)$ at the splenic hilum. A pRCT would help devise optimal therapeutic strategies for tumors invading the greater curvature side of the stomach.

\section{Conflicts of Interest}

The Authors declare no conflicts of interest.

\section{Authors' Contributions}

$\mathrm{KC}$, EI conceived the study; KC designed the study; SS, TN, KH, $\mathrm{KK}$, and $\mathrm{KT}$ acquired the data; $\mathrm{AH}$ and $\mathrm{WJ}$ analyzed and interpreted the data; ST and TK performed quality control of data and algorithms; $\mathrm{KC}$ and MT performed statistical analysis; $\mathrm{KC}$ and SS prepared the manuscript; $\mathrm{KC}$ and EI edited the manuscript; KC, SS, TN, KH, WJ, ST, TK, KK, KT, AH, EI and MT reviewed the manuscript.

\section{References}

1 Torre LA, Siegel RL, Ward EM and Jemal A: Global cancer incidence and mortality rates and trends-an update. Cancer Epidemiol Biomarkers Prev 25(1): 16-27, 2016. PMID: 26667886. DOI: $10.1158 / 1055-9965$.EPI-15-0578

2 World Health Organization. Global Cancer observatory: Cancer today. Lyon, France: International Agency for Research on Cancer; 2018. Available at: https://gco.iarc.fr/today

3 Ahn HS, Lee HJ, Yoo MW, Jeong SH, Park DJ, Kim HH, Kim WH, Lee KU and Yang HK: Changes in clinicopathological features and survival after gastrectomy for gastric cancer over a 20-year period. Br J Surg 98(2): 255-260, 2011. PMID: 21082693. DOI: $10.1002 /$ bjs.7310

4 Japanese Gastric Cancer Association: Japanese gastric cancer treatment guidelines 2014 (ver. 4). Gastric Cancer 20(1): 1-19, 2017. PMID: 27342689. DOI: 10.1007/s10120-016-0622-4

5 Yamamoto M, Baba H, Kakeji Y, Endo K, Ikeda Y, Toh Y, Kohnoe S, Okamura $\mathrm{T}$ and Maehara $\mathrm{Y}$ : Postoperative morbidity/mortality and survival rates after total gastrectomy, with splenectomy/pancreaticosplenectomy for patients with advanced gastric cancer. HepatoGastroenterol 51(55): 298-302, 2004. PMID: 15011889.

6 Biffi R, Chiappa A, Luca F, Pozzi S, Lo Faso F, Cenciarelli S, Andreoni B: Extended lymph node dissection without routine spleno-pancreatectomy for treatment of gastric cancer: low morbidity and mortality rates in a single center series of 250 patients. J Surg Oncol 93(5): 394-400, 2006. PMID: 16550575, DOI: $10.1002 /$ jso. 20495 
7 Goto H, Tokunaga M, Sugisawa N, Tanizawa Y, Bando E, Kawamura T, Niihara M, Tsubosa Y and Terashima M: Value of splenectomy in patients with Siewert type II adenocarcinoma of the esophagogastric junction. Gastric Cancer 16(4): 590-595, 2013. PMID: 23179369. DOI: 10.1007/s10120-012-0214-x

8 Kunisaki C, Makino H, Suwa H, Sato T, Oshima T, Nagano Y, Fujii S, Akiyama H, Nomura M, Otsuka Y, Ono HA, Kosaka T, Takagawa $\mathrm{R}$, Ichikawa $\mathrm{Y}$ and Shimada $\mathrm{H}$ : Impact of splenectomy in patients with gastric adenocarcinoma of the cardia. J Gastrointest Surg 11(8): 1039-1044, 2007. PMID: 17514409. DOI: $10.1007 / \mathrm{s} 11605-007-0186-\mathrm{z}$

9 Jeong O, Jung MR and Ryu SY: Clinicopathological features and prognostic impact of splenic hilar lymph node metastasis in proximal gastric carcinoma. Eur J Surg Oncol 45(3): 432-438, 2019. PMID: 30389304. DOI: 10.1016/j.ejso.2018.10.531

10 Watanabe M, Kinoshita T, Enomoto N, Hidehito Shibasaki and Toshirou Nishida: Clinical significance of splenic hilar dissection with splenectomy in advanced proximal gastric cancer: An analysis at a single institution in Japan. World J Surg 40(5): 1165-1171, 2016. PMID: 26630939. DOI: 10.1007/s00268-015-3362-4

11 Erturk S, Ersan Y, Cicek Y, Dogusoy D and Senocak M: Effect of simultaneous splenectomy on the survival of patients undergoing curative gastrectomy for proximal gastric carcinoma. Surg Today 33(4): 254-258, 2003. PMID: 12707818. DOI: $10.1007 / \mathrm{s} 005950300057$

12 Sano T, Sasako M, Mizusawa J, Yamamoto S, Katai H, Yoshikawa T, Nashimoto A, Ito S, Kaji M, Imamura $\mathrm{H}$, Fukushima N and Fujitani K: Randomized controlled trial to evaluate splenectomy in total gastrectomy for proximal gastric carcinoma. Ann Surg 265 (2): 277-283, 2017. PMID: 27280511. DOI: $10.1097 /$ SLA.0000000000001814

13 Yura M, Yoshikawa T, Otsuki S, Yamagata Y, Morita S, Katai H and Nishida T: The therapeutic survival benefit of splenic hilar nodal dissection for advanced proximal gastric cancer invading the greater curvature. Ann Surg Oncol 26(3): 829-835, 2019. PMID: 30569298. DOI: 10.1245/s10434-018-07122-9

14 Agha RA, Fowler AJ, Limb C, Whitehurst K, Coe R, Sagoo H, Jafree DJ, Chandrakumar C and Gundogan B: Impact of the mandatory implementation of reporting guidelines on reporting quality in a surgical journal: A before and after study. Int J Surg 30: 169-172, 2016. PMID: 27112835. DOI: 10.1016/j.ijsu.2016.04.032

15 Shea BJ, Reeves BC, Wells G, Thuku M, Hamel C, Moran J, Moher D, Tugwell P, Welch V, Kristjansson E and Henry DA: AMSTAR 2: a critical appraisal tool for systematic reviews that include randomised or non-randomised studies of healthcare interventions, or both. BMJ 358: j4008, 2017. DOI: 10.1136/bmj.j4008

16 Furukawa H, Hiratsuka M, Ishikawa O, Ikeda M, Imamura H, Masutani S, Tatsuta M and Satomi T: Total gastrectomy with dissection of lymph nodes along the splenic artery: a pancreaspreserving method. Ann Surg Oncol 7(9): 669-73, 2000. PMID: 11034244. DOI: $10.1007 / \mathrm{s} 10434-000-0669-6$

17 Yu W, Choi GS and Chung HY: Randomized clinical trial of splenectomy versus splenic preservation in patients with proximal gastric cancer. Br J Surg 93(5): 559-563, 2006. PMID: 16607678. DOI: 10.1002/bjs.5353

18 Csendes A, Burdiles P, Rojas J, Braghetto I, Diaz JC and Maluenda F: A prospective randomized study comparing D2 total gastrectomy versus D2 total gastrectomy plus splenectomy in 187 patients with gastric carcinoma. Surgery 131(4): 401-407, 2002. PMID: 11935130. DOI: 10.1067/msy.2002.121891
19 Kwon SJ: Prognostic impact of splenectomy on gastric cancer: Results of the Korean Gastric Cancer Study Group. World J Surg 21(8): 837-844, 1997. PMID: 9327675. DOI: 10.1007/ s002689900314

20 Lee KY, Noh SH, Hyung WJ, Lee JH, Lah KH, Choi SH and Min JS: Impact of splenectomy for lymph node dissection on long-term surgical outcome in gastric cancer. Ann Surg Oncol 8(5): 402-406, 2001. PMID: 11407513. DOI: 10.1007/s10434-001-0402-0

21 Oh SJ, Hyung WJ, Li C, Song J, Kang W, Rha SY, Chung HC, Choi SH and Noh SH: The effect of spleen-preserving lymphadenectomy on surgical outcomes of locally advanced proximal gastric cancer. J Surg Oncol 99(5): 275-280, 2009. PMID: 19152367. DOI: 10.1002/jso.21229

22 Jeong O, Kim HG, Ryu SY, Young KP and Mi RJ: Adverse prognostic impact of splenectomy on survival in gastric carcinoma patients: Regression and propensity score matching analysis of 1074 patients. PLoS One 13(9): e0203820, 2018. DOI: 10.1371/journal.pone.0203820

23 Zhang CH, Zhan WH, He YL, Chen CQ, Huang MJ and Cai SR: Spleen preservation in radical surgery for gastric cardia cancer. Ann Surg Oncol 14(4): 1312-1319, 2007. PMID: 17265118. DOI: $10.1245 / \mathrm{s} 10434-006-9190 \mathrm{xxx}$

24 Wang F, Kang Y, Zu HL, Jiang H, Zhu L, Dong PD and Xue YW: Clinicopathologic characteristics and prognosis of gastric cancer patients underwent gastrectomy combined with splenectomy. Hepatogastroenterol 61(136): 2434-2437, 2014. PMID: 25699398

25 Zhang H, Pang D, Xu H, Ren Y and Liu C: Is concomitant splenectomy beneficial for the long-term survival of patients with gastric cancer undergoing curative gastrectomy? A singleinstitution study. World J Surg Oncol 12: 193, 2014. DOI: 10.1186/1477-7819-12-193

26 Fatouros M, Roukos DH, Lorenz M, Arampatzis I, Hottentrott C, Encke A and Kappas AM: Impact of spleen preservation in patients with gastric cancer. Anticancer Res 25(4): 3023-3030, 2005. PMID: 16080561.

27 Sasada S, Ninomiya M, Nishizaki M, Harano M, Ojima Y, Matsukawa H, Shiozaki S, Ohno S, Takakura N: Frequency of lymph node metastasis to the splenic hilus and effect of splenectomy in proximal gastric cancer. Anticancer Res 29(8): 3347-3351, 2009. PMID: 19661354

28 Nashimoto A, Yabusaki $\mathrm{H}$ and Matsuki A: The significance of splenectomy for advanced proximal gastric cancer. Int J Surg Oncol 2012: 301530, 2012. PMID: 22685639. DOI: 10.1155/ 2012/301530

29 Fang WL, Huang KH, Wu CW, Chen JH, Lo SS, Hsieh MC, Shen $\mathrm{KH}$ and Li AF: Combined splenectomy does not improve survival in radical total gastrectomy for advanced gastric cardia cancer. Hepatogastroenterol 59(116): 1150-1154, 2012. PMID: 22580669. DOI: $10.5754 /$ hge 10429

30 Wang F, Chang YC, Chen TH, Hsu JT, Kuo CJ, Lin CJ, Chen JS, Chiang KC, Yeh TS, Hwang TL and Jan YY: Prognostic significance of splenectomy for patients with gastric adenocarcinoma undergoing total gastrectomy: A retrospective cohort study. Int J Surg 12(6): 557-565, 2014. PMID: 24793232. DOI: 10.1016/j.ijsu.2014.04.006

31 Yao XX, Sah BK, Yan M, Chen MM and Zhu ZG: Radical gastrectomy with combined splenectomy: Unnecessary. Hepatogastroenterol 58(107-70): 1067-1070, 2011. PMID: 21830444. 
32 Son SY, Shin DJ, Park YS, Oo AM, Jung DH, Lee CM, Ahn SH, Park DJ and Kim HH: Spleen-preserving lymphadenectomy versus splenectomy in laparoscopic total gastrectomy for advanced gastric cancer. Surg Oncol 26(2): 207-211, 2017. PMID: 28577727. DOI: 10.1016/j.suronc.2017.04.002

33 Hong ZL, Chen QY, Zheng CH, Li P, Xie JW, Wang JB, Lin JX, Lu J, Cao LL, Lin M, Tu RH and Huang CM: A preoperative scoring system to predict the risk of no.10 lymph node metastasis for advanced upper gastric cancer: A large case report based on a single-center study. Oncotarget 8(45): 80050-80060, 2017. PMID: 29108387. DOI: $10.18632 /$ oncotarget.17273

34 Ohkura Y, Haruta S, Shindoh J, Tanaka T, Ueno M and Udagawa $\mathrm{H}$ : Efficacy of prophylactic splenectomy for proximal advanced gastric cancer invading greater curvature. World J Surg Oncol 15(1): 106, 2017. PMID: 28545537. DOI: 10.1186/s12957-017-1173-9

35 Kano Y, Ohashi M, Ida S, Kumagai K, Makuuchi R, Sano T, Hiki $\mathrm{N}$ and Nunobe $\mathrm{S}$ : Therapeutic value of splenectomy to dissect splenic hilar lymph nodes for type 4 gastric cancer involving the greater curvature, compared with other types. Gastric Cancer 23(5): 927-936, 2020. PMID: 32307689. DOI: $10.1007 / \mathrm{s} 10120-020-01072-6$
36 Nakata K, Nagai E, Ohuchida K, Shimizu S and Tanaka M: Technical feasibility of laparoscopic total gastrectomy with splenectomy for gastric cancer: Clinical short-term and longterm outcomes. Surg Endosc 29(7): 1817-1822, 2015. PMID: 25318360. DOI: $10.1007 / \mathrm{s} 00464-014-3870-6$

37 Usui S, Tashiro M, Haruki S, Arita K, Ito K, Matsumoto A and Takiguchi N: Spleen preservation versus splenectomy in laparoscopic total gastrectomy with D2 lymphadenectomy for gastric cancer: A comparison of short-term outcomes. Asian J Endosc Surg 9(1): 5-13, 2016. PMID: 26551257. DOI: 10.1111/ ases. 12255

38 Yang K, Cho M, Roh CK, Seo WJ, Choi S, Son T, Kim HI and Hyung WJ: Robotic spleen-preserving splenic hilar lymph node dissection during total gastrectomy for gastric cancer. Surg Endosc 33(7): 2357-2363, 2019. PMID: 30945060. DOI: $10.1007 / \mathrm{s} 00464-019-06772-4$

Received September 16, 2020

Revised October 2, 2020

Accepted October 7, 2020 